\title{
Reflexiones sobre los delitos electorales y la FEPADE a partir de la alternancia política (2000 al 2012)
}

\author{
Reflections on Electoral Crimes and FEPADE after \\ the Political Alternation (2000 to 2012)
}

\section{Héctor Díaz-Santana*}

\section{Sumario:}

I. Introducción

II. Qué son los delitos electorales

III. Evolución de los delitos electorales

IV. Los tipos penales electorales y las penas

V. Los doce años de justicia penal electoral en México (2000 al 2012)

VI. Los recursos humanos y financieros de la FEPADE

VII. Las averiguaciones previas que recibe la FEPADE

VIII. Las determinaciones jurídicas de la FEPADE

IX. Los procesos penales electorales

$X$. Los delitos electorales en su relación con los derechos difusos y colectivos

$\mathrm{XI}$. Conclusiones

XII. Bibliografía

* Abogado por la Universidad de Guadalajara y doctor en Derecho por la Universidad Complutense de Madrid; investigador del Centro de Investigaciones Económicas, Sociales y Administrativas (CIECAS-IPN); profesor en la FCPyS de la UNAM, y miembro del Sistema Nacional de Investigadores. 


\section{Resumen:}

El artículo hace un análisis de los delitos electorales en México y del desempeño de la Fiscalía Especializada para la Atención de Delitos Electorales (FEPADE) durante el periodo 2000 al 2012. En este lapso la institución no ha podido legitimar su ejercicio, son mínimas las sanciones que impone a los delincuentes electorales y su papel es secundario en comparación con el IFE y el TEPJF. La FEPADE carece de un marco legal adecuado, un presupuesto suficiente y no cuenta con autonomía institucional. Además el demostrar la comisión de un delito electoral es una tarea compleja, la compra, coacción y manipulación del voto son conductas que se realizan en la clandestinidad, casi no se denuncian y en muchos casos el votante acepta la oferta del partido porque obtiene un beneficio económico o en especie. Esta acción que es equiparable a una afectación directa a los derechos difusos y colectivos de los ciudadanos, genera un daño irreparable a las elecciones y es parte de la responsabilidad que tutela la FEPADE. Al final del artículo se reflexiona sobre algunas propuestas que podrían ser viables para hacer más efectiva la procuración de justicia penal electoral en México.

\section{Abstract}

The paper analyzes electoral crimes in Mexico and the performance by the Office of the Special Prosecutor of Electoral Crimes (Fiscalía Especializada para la Atención de Delitos Electorales, FEPADE) during the period between 2000 and 2012. During this time, the institution could not fulfill its purpose, the sanctions imposed against electoral offenders were minimal and its role was secondary to that of IFE and the Electoral Tribunal. The FEPADE lacks an adequate legal framework, its budget is insufficient and it also lacks institutional autonomy. To make things more difficult, proving an electoral crime is a complex task since vote buying, coercion and vote rigging are behaviors that are done in secret. These events are rarely reported and, in many cases, the voter accepts the offer by the offender because the voter receives a financial reward or a payment in kind. The occurrence of these actions is comparable to having a detrimental effect on the diffuse interests and collective rights of citizens. They irreversibly taint the elections and lie within the responsibilities assigned to FEPADE. At the end of the article we examine some potentially viable proposals for more effective electoral law enforcement in Mexico.

Palabras claves: Fiscalía Especializada para la Atención de Delitos Electorales (FEPADE), delitos electorales, Justicia penal electoral, derechos difusos y colectivos, compra y coacción del voto, fraude electoral.

Descriptors: Special Prosecutor in Electoral Crimes, electoral crimes, electoral criminal justice, diffuse and collective rights, vote buying and coercion, electoral fraud. 


\section{Introducción}

La transición democrática en México se sustentó principalmente en la construcción de un sistema electoral que garantizara la pluralidad política a través de instituciones y normas, por tal motivo existe una amplia literatura en los temas de administración y justicia electoral. Sin embargo, en lo referente a los delitos electorales y el desempeño de la Fiscalía Especializada para la Atención de Delitos Electorales (FEPADE), se manifestaron claros contrastes, el Código Penal Federal en materia de delitos electorales no se ha reformado desde 1996, la FEPADE tiene un presupuesto limitado, los estudios en la materia son aislados y las publicaciones académicas mínimas. Lo anterior nos obliga a hacer la primera conclusión: la justicia penal electoral fue relegada de la institucionalidad electoral del país.

Hacer una evaluación sobre la justicia penal electoral desde el año 2000 no es una tarea fácil y más porque el que suscribe fue funcionario de la FEPADE. Ello me da una ventaja de conocer a la institución y también un compromiso por mantener la objetividad. Lo que sí puedo afirmar es que la FEPADE desempeña un papel complejo, es la responsable de "meter a la cárcel a los criminales electorales" que actuaron de manera delictiva en situaciones de competencia electoral, en donde generalmente hay grupos políticos que denuncian y otros que son acusados. En síntesis, la FEPADE, como el Instituto Federal Electoral (IFE) y el Tribunal Electoral del Poder judicial de la Federación (TEPJF), es una institución que permanentemente está sometida a fuertes presiones políticas y mediáticas.

Una de las desventajas de la FEPADE es que depende orgánicamente de la Procuraduría General de la República y en consecuencia del Ejecutivo Federal. Ello produce acusaciones constantes por falta de imparcialidad, como consecuencia de pensar que no sancionará a miembros del partido en el gobierno. Esta es una característica que marca una clara diferencia con el IFE y el TEPJF los que orgánicamente cuentan con autonomía de ejercicio.

Lo que es un hecho, es que la FEPADE constituye una pieza necesaria para el entramado institucional. El sistema electoral mexicano aunque ha evolucionado en su parte orgánica e instrumental, se ha rezagado en la parte funcional. Las elecciones se siguen cuestionando, las acusaciones por alterar la legalidad son constantes y se presentan 
miles de recursos al año ante los tribunales electorales. Cuando un sistema electoral se institucionaliza, los candados y los sistemas de fiscalización se van eliminando y en México por el contrario constantemente se incrementan.

Lo ideal sería que no existiera un organismo como la FEPADE y que los posibles delitos electorales sean atendidos por la justicia criminal ordinaria. En la mayoría de países europeos no se contemplan entidades ad hoc para la justicia electoral, pero también es cierto que no se necesitan, en las elecciones prácticamente son inexistentes las denuncias por delitos electorales.

La pregunta sería para qué el sistema electoral mexicano diseñó una institución como la FEPADE, la respuesta es porque era necesaria por las condiciones en que se desarrollaban las elecciones. Para la transición democrática era fundamental establecer un andamiaje institucional potente capaz de garantizar condiciones óptimas de la competencia electoral y evitar que conductas como la compra y coacción del voto fueran una constante y alteraran la voluntad popular expresada en las urnas y afectaran la legitimidad electoral. ${ }^{1}$

En las negociaciones efectuadas a finales de la década de los ochenta, una petición unánime de la oposición fue castigar toda conducta constitutiva de "fraude electoral". El IFE y el TEPJF no estaban facultados para iniciar procedimientos penales, por ello fue necesario incluir en la trilogía electoral a la FEPADE y dotarla de autonomía técnica para garantizar un desempeño imparcial. Desde su nacimiento su papel en el engranaje institucional fue pequeño, pero relevante, tenía a su cargo sancionar y en su caso prevenir la comisión de conductas que afectaran la imparcialidad manifestada por la falta de garantías para el voto libre y secreto.

Una pretensión del sistema electoral mexicano de la década de los ochenta, era erradicar conductas fraudulentas, pero sobre todo las escandalosas como eran el relleno de urnas (embarazo), las votaciones masivas con credenciales de elector que no correspondían al ciudadano y la alteración de las actas electorales. Para estas acciones el derecho penal era el indicado, se trata del ejercicio de uno de sus principios básicos, la última ratio punitiva, dicho de otra manera, como el ius pu-

1 Díaz Santana, Héctor, "La importancia de los delitos electorales en el sistema electoral de México", en Estrada Camargo, Manuel y Sáenz López, Karla (coords.), Elecciones, gobierno y gobernabilidad, México, Instituto Federal Electoral-Universidad Autónoma de Nuevo León, 2010, p. 67. 
niendi, como elemento que reprime, sanciona o castiga una conducta que daña severamente al Estado y a la sociedad en su conjunto. Es decir, las personas que alteraran de manera grave los principios constitucionales de las elecciones serían sancionados con pena privativa de la libertad, multas o inhabilitación para ocupar cargos públicos.

Actualmente la configuración normativa de los delitos electorales es obsoleta, data de 1994 y 1996, y no obstante que cada cuatro años se reforma el Código Electoral, las condiciones de la competencia política han cambiado y la sociedad ha evolucionado en sus prácticas electorales, la configuración de los delitos electorales como lo expresamos anteriormente no se ha modificado.

A los delitos electorales los debemos concebir bajo otra óptica, si es que pretendemos que estos incidan en la pulcritud electoral. Tenemos que cambiar la percepción del presente, que se concibe bajo una óptica que sólo castiga las conductas fraudulentas de las elecciones y perseguir una posición hacia el futuro; qué va a pasar si en las elecciones se siguen cometiendo actos que afectan gravemente a la imparcialidad y legalidad electoral. Para esto afirmo que los delitos electorales tienen una analogía a los delitos difusos y colectivos, que en términos simples los podemos definir como las acciones que se realizan de manera reiterada produciendo daños leves que no se aprecian en el momento, pero con el pasar del tiempo se van acumulando generando perjuicios severos y graves riesgos a la sociedad en su conjunto. Un ejemplo de ello es la afectación al medio ambiente, si un grupo de personas sistemáticamente tiran la basura al río en unos años estará contaminado y enfermará a la población que consume el agua. Si la sociedad no respeta las reglas de las elecciones y periódicamente se acostumbra a violentar la ley, llegará el momento que esa conducta se vea como normal y tenga una incidencia progresiva que en algún momento creará una crisis o la ruptura del sistema electoral. En los últimos años hemos observado la carencia de ideas y de debates, el clientelismo y la compra del voto son denunciadas de manera permanente y las acciones de proselitismo se ven influidas por regalos sobre todo en zonas de marginalidad social en donde "no hay campaña electoral sin despensa".

En el presente ensayo será menester dar una concepción global del entorno del derecho penal electoral y de la FEPADE desde el año 2000 a la fecha. Para este fin será necesario incluir datos estadísticos que quizá no favorezcan al rendimiento institucional de la FEPADE, sin 
embargo, en su defensa también seré muy enfático, al señalar que la ciudadanía casi no denuncia conductas constitutivas de delitos electorales, los cuales son de querella y si estas no existen, complican la labor de la FEPADE, se le exigen resultados cuando no tienen la forma de iniciar un proceso criminal. Por lo anterior, las conclusiones serán una reflexión sobre el futuro de esta institución en el sistema electoral del país.

\section{Qué son los delitos electorales}

Son pocos los autores que se ha atrevido a definir los delitos electorales, puesto que puede ser una tarea complicada, por sus múltiples facetas e implicaciones como institución de derecho público y en la protección y tutela de los derechos políticos. Orozco y Silva, afirman que los delitos electorales representan características comunes a los derechos políticos porque inciden directamente en el ámbito del poder. ${ }^{2}$ Por su parte, Montoro señala una figura interesante como son los delitos políticos, los que se configuran cuando afectaban al monarca o al Estado "lesa majestad" y vulneran al "régimen jurídico-político". Estas acciones pueden partir de realidades complejas, puesto que implican dimensiones de la legitimidad, la positividad (legalidad) y la eficacia, que son más amplias y no se limitan a la disputa del poder. ${ }^{3}$

Los delitos electorales están insertos en el eslabón inicial del ejercicio público o la representación política, puesto que tutelan el derecho individual y colectivo de los ciudadanos para elegir a sus gobernantes. Para González de la Vega, estos tienen como función tutelar la libertad del voto, la honestidad del proceso electoral y la sinceridad del sufragio universal. ${ }^{4}$ A mi juicio esta definición es precisa, los delitos electorales tiene como cometido tutelar el voto libre y secreto y evi-

2 Orozco Henriquez, J. Jesús y Silva Adaya, Juan Carlos, “El régimen represivo electoral (con especial referencia a las sanciones administrativas), Revista Mexicana de Justicia, Sexta Época, núm. 3, 2002, p. 375.

3 Montoro Ballesteros, Alberto, "En torno a la idea de delito político (Notas para una ontología de los actos contrarios a Derecho)", Anales de Derecho, Universidad de Murcia, núm. 18, 2000, p. 131.

4 González de la Vega, René, Derecho penal electoral, 3a. ed., México, Porrúa, 1994, p. 231. 
tar presiones, coacciones o conductas que alteren la voluntad popular. Al mismo tiempo tienen como cometido proteger que la voluntad popular no se altere, por circunstancias que modifiquen el resultado electoral como consecuencia de conteos irregulares, alteraciones a la documentación electoral o fraudes burdos.

Una característica especial de los delitos electorales es el bien jurídico que tutelan, la libertad del individuo para elegir a sus gobernantes. El derecho penal tiene como objeto castigar a las personas que agredan la integridad física del individuo, su patrimonio o libertad. A diferencia de otros delitos, el grave problema de los delitos electorales es que su comisión generalmente no se percibe como una agresión o menoscabo, por eso no se denuncian, ${ }^{5}$ es decir, quebranta el principio democrático de la representación y la garantía del voto libre y secreto. ${ }^{6}$ En estricto sentido, los delitos electorales tienen una doble función: tutelan el proceso electoral en general y las garantías políticas de los ciudadanos. $^{7}$

\section{Evolución de los delitos electorales}

La historia de los delitos electorales en México es bastante longeva, tanto es así que nace a la par de las primeras reglas electorales que se establecieron en el siglo XIX para elegir al Constituyente de Cádiz. Ello era necesario para evitar circunstancias graves que afectaran la integridad electoral, en esa época en todos los países que se celebraban elecciones se manifestaban anomalías que favorecían a los grupos de poder. ${ }^{8}$ En Estados Unidos las elecciones estaban plagadas de irregularidades, el voto se compraba, a los votantes se les presionaba y los

5 La aseveración se sostiene con base en las entrevistas en profundidad realizadas en el proyecto "Las condiciones del voto libre y secreto en las elecciones federales del 2 de julio del 2000, FLACSO, México, www.ife.org.mx/documentos/.../participacion_ciuda dana.pdf.

6 Díaz Santana, Héctor, "El ejercicio de las instituciones electorales en la manipulación del voto en México", Perfiles Latinoamericanos, núm. 20, junio de 2002, México, p. 113.

7 Reyes Tayabas, Jorge, Análisis de los delitos electorales y criterios aplicativos, México, PGR, 1994, p. 20.

8 Toqueville, Alexis de, La democracia en América, México, Fondo de Cultura Económica, 1994, pp. 192-195. 
colegios electorales se manipulaban. En otros países, las elecciones era sólo un trámite para legitimar el gobierno en turno, de cualquier forma como lo expresa López Pintor "el fraude electoral ha existido desde mediados y finales del siglo XIX". 9 Por ello, el fraude electoral en aquel tiempo no era solamente costumbre nacional, el problema es que en algunos países sus sistemas electorales se sofisticaron y garantizaron los valores esenciales de la democracia representativa, pero en México perduran hasta la fecha.

$\mathrm{Si}$ afirmamos que los delitos electorales son tan longevos como las primeras instituciones electorales, fue porque a la par de las normas que definían el sistema electoral, que incluían sanciones cuya configuración actual es similar a los establecidos por la justicia penal electoral. Esta circunstancia se mantuvo por más de 170 años, pese a ello, nunca entraron en operación, las sanciones siempre se imponían de los grupos de poder a los opositores. En síntesis, estuvieron invernando o congelados hasta que resurgieron de la mano de la reforma electoral de 1994.

Aunque tenemos delitos electorales estructuralmente configurados desde siglos atrás, estos en la práctica son relativamente jóvenes, puesto que su aplicación estaba supeditada a la dinámica y desarrollo de las inercias democráticas del proceso de transición política, el que en sus inicios reclamaba procesos electorales limpios y apegados a la legalidad electoral. En los últimos 20 años los delitos electorales evolucionaron de manera normativa, como lo señala Fromow, los delitos electorales tienen sus precedentes legislativos en más de 70 legislaciones diferentes, ${ }^{10}$ sin embargo, el problema que a la fecha se tiene es su déficit de efectividad, casi son inexistentes las personas que se sancionan por ello, en un país que los procesos electorales están plagados de irregularidades.

Los delitos electorales en su devenir histórico los podemos clasificar en cuatro épocas. ${ }^{11}$ En la primera época, "Periodo inicial (siglo XIX a 1990)", la Constitución de Cádiz y la de Apatzingán estable-

9 López Pintor, Rafael, El fraude electoral en las democracias emergentes: conceptos básicos para una evaluación, Washington DC, IFES, 2010, p. 5.

10 Fromow, María de los Ángeles, "Los delitos electorales en México", Revista Mexicana de Justicia, Sexta Época, núm. 3, 2002, p. 81.

11 Díaz Santana, Héctor, "La importancia de los delitos electorales en el sistema electoral de México", cit., pp. 72-74. Este modelo se tomó como referencia pero se realizó un ajuste en su estructura y fechas. 
cían sanciones privativas de la libertad a las personas que cometieran irregularidades en las mesas electorales y a los que ejercieran ciertos actos que vulneraran el voto libre. ${ }^{12}$ Posterior a ello se tipificaron en diversas legislaciones pero su operatividad fue prácticamente nula ya que no existen evidencias de personas sancionadas por estos motivos. En la segunda época "Periodo de la instauración (1994-2000)", como consecuencia de las reiteradas acusaciones de la oposición de elecciones fraudulentas, una de las adiciones más importantes de la reforma electoral de 1989-90, fue la creación de un apartado especial en el Código Penal Federal (Título Vigésimo Cuarto), que se reformó sustancialmente en 1994 y se ajustó en 1996. En total la estructura operacional se formuló con base en 13 artículos (del 401 al 413), que manifiestan casi 160 figuras delictivas. También se integraron penas más severas como la prisión, inhabilitación para ocupar cargo público, sanción económica e inhabilitación para ocupar cargo público. ${ }^{13}$ Un aspecto sustancial fue la creación de la Fiscalía Especializada para la Atención de los Delitos Electorales (FEPADE) en 1994. ${ }^{14}$

La tercera época "Periodo de consolidación (2001-2004), se manifiesta después de la alternancia en donde la FEPADE tiene una mayor visibilidad pública y se desarrollan diversas campañas de información sobre delitos electorales. En esos tiempos el IFE y el TEPJF, estaban perfectamente posicionados, tenían niveles altos de legitimidad social y eran reconocidas como instituciones eficaces. Diferente a ello era la FEPADE, una institución prácticamente desconocida, además las denuncias que se recibían por la comisión de delitos electorales eran mínimas en relación con su posible incidencia. ${ }^{15}$ Por la situación existente, a partir de 2001 se decidió cambiar la estrategia, para ello se

12 Un estudio pormenorizado de la evolución del derecho penal electoral puede consultarse en: Esparza, Bernardino, Constitucionalización de los delitos electorales en la legislación mexicana, 1812-2009, México, Instituto Nacional de Ciencias Penales, 2009.

${ }_{13}$ Los delitos electorales al no ser graves, inmediatamente el inculpado puede gozar del beneficio de la libertad bajo caución y en caso de ser condenado puede permutar la pena. Solamente en el supuesto de acumulación de delitos, la condena que puede imponerse impide los beneficios señalados.

14 Para conocer con amplitud los sucesos que dieron origen a la FEPADE, véase: Pérez Fernández del Castillo, Germán et al. (comps.), Memoria histórica de la transición democrática en México (1977-2007). Documentos básicos para entender el cambio político, México, Porrúa, 2009, t. II, pp. 603-637.

15 Díaz Santana, Héctor, "El ejercicio de las instituciones electorales en la manipulación del voto en México", cit., pp. 115-122. 
realizaron campañas de posicionamiento público, se reestructuró orgánicamente la FEPADE y se desarrollaron acciones de prevención del delito electoral en elecciones federales y locales. ${ }^{16}$ Un suceso relevante que proyectó a la FEPADE fueron los casos "Pemexgate" y "Amigos de Fox". En la cuarta etapa, "Exigencias a la FEPADE” (2004-2012), los actores políticos y sociales demandaron mayor efectividad a la institución. El tener un mayor posicionamiento público de la FEPADE propició que al mismo tiempo actores políticos, sociales y mediáticos, demandaran como evidencia de la efectividad de su trabajo, sanciones ejemplares a personas que cometieron delitos electorales. Ello era complicado, la ley era prácticamente obsoleta. Es por ello que en 2004 se presentaron por parte del Ejecutivo Federal diversas iniciativas para reformar el Código Penal Federal que en síntesis proponía aumentar los tipos penales y las sanciones. ${ }^{17} \mathrm{~A}$ partir de esas fechas fueron constantes los intentos de la FEPADE por reformar los delitos electorales, se presentaron sin éxito propuestas en los años 2005, 2008, 2010 y 2011. Los legisladores no modificaron la ley porque les permitía un amplio margen de ejercicio en acciones que vulneraban el voto libre y secreto. El resultado fue que las elecciones de 2006, 2009 y 2012 se caracterizaron por un juego rudo que no se sancionó, se denunciaron prácticas ilícitas de todos los bandos y el tema de la compra del voto y el uso de los recursos públicos fue abiertamente cuestionado.

\section{Los tipos penales electorales y las penas}

La configuración normativa de los delitos electorales en México se caracteriza por sancionar las conductas que afectan de manera grave los principios constitucionales del voto. Si utilizamos el término grave es porque principalmente sanciona las conductas que se manifestaron durante la década de los ochenta consideradas como fraudulentas. La estructura jurídico-dogmática de los tipos penales electorales, también puede concebirse en la normativa administrativa electoral como una conducta que afecta a la competencia equitativa, es por eso que

16 Entrevista con María de los Ángeles Fromow, fiscal especial para la Atención de los Delitos Electorales del periodo 2001-2006, celebrada en mayo de 2003.

17 http://www.pgr.gob.mx/fepade/reforma\%20penal\%20electoral.asp. 
existe una línea tenue entre lo penal y administrativo, que en palabras de Barreiro constituye un "buen matrimonio" que se toma de la mano en un mismo acto y después se separa pero que en cualquier momento puede llegar a confundirse, sin embargo los dos afectan directamente al proceso electoral. ${ }^{18}$ Por este motivo, es común que los ciudadanos puedan confundir una falta administrativa o un hecho político con un delito electoral. Por ejemplo, algunos ciudadanos consideran que llamar a una casa para hacer proselitismo político es un delito electoral. ${ }^{19}$ Es decir, en algunos sectores amplios del imaginario social, toda conducta que afecte el voto libre y secreto a veces se concibe como delito electoral.

La configuración actual de los delitos electorales está clasificada dependiendo de la persona que comete el ilícito: particulares, funcionarios electorales o partidistas, candidatos, organizadores de actos de campaña, ministros de cultos religiosos, servidores públicos, y diputados y senadores electos y se sanciona dependiendo de la gravedad del hecho en el proceso electoral, el ius puniendi. El objeto es sancionar e inhibir conductas, agresiones y faltas que lastimen gravemente a las elecciones.

Toda norma penal tutela un bien jurídico, en materia electoral de manera genérica comprende la organización y realización de los procesos electorales para elegir al titular del Poder Ejecutivo Federal, diputados federales y senadores de la República. Esta acción también tiene correlación en el ámbito estatal, en síntesis tenemos delitos electorales federales y estatales, pero ambos castigan fundamentalmente las conductas que afectan al sufragio universal, libre, secreto, directo, personal, intransferible y el proceso de organización electoral.

Los delitos electorales principalmente operan bajo la lógica del dolo, no puede haber delitos electorales culposos. El dolo de acuerdo a Zaffaroni consiste en el actuar consiente y voluntario, dirigido a la producción de un resultado típico y antijurídico "es decir la voluntad realizadora del tipo objetivo". ${ }^{20}$ La configuración actual de los delitos electorales federales se agrupan en más de 160 hipótesis delictivas las

18 Barreiro Pereda, Francisco, "Los delitos electorales en la legislación penal mexicana”, Justicia Electoral, vol. II, núm. 3, 1993, p. 21.

19 Durante 2006 se reportaron al teléfono de atención ciudadana de la FEPADE más de 20 llamadas que denunciaban esta conducta como delito.

20 Zaffaroni, Eugenio Raúl, Manual de Derecho Penal, México, Cárdenas Editor y Distribuidor, 1991, p. 428. 
que se pueden dividir en tres apartados: contra la libertad del sufragio; contra la certeza de los resultados y contra la equidad de la contienda electoral.

En materia de sanciones por la comisión de delitos electorales se sintetizan en lo siguiente: pena privativa de la libertad, multas, suspensión de derechos políticos y destitución de cargos públicos. Como se mencionó anteriormente, los delitos electorales federales no se consideran graves. Los delitos señalados en el Título Vigesimocuarto, Capítulo Único del Código Penal Federal, imponen las penas que oscilan entre 6 meses y 9 años, salvo a los ministros de culto religioso, a quienes se les impondrá multa y a los senadores y diputados federales que no se presenten a la toma de protesta de su cargo, se les puede suspender sus derechos políticos hasta por seis años (artículo 408).

\section{Los doce años de justicia penal electoral en México (2000-2012)}

Hacer un análisis de valoración de la justicia electoral en México tiene una alta complejidad, ya que no sólo se debe valorar el ejercicio de las instituciones, sino también el de los actores vinculados a su ejercicio. Esta labor es compleja, sin embargo, desde ahora se puede afirmar que la compra y coacción del voto es un comportamiento que está latente en las elecciones. El determinar su intensidad es complejo, los estudios realizados por centros de investigación y por organizaciones de la sociedad civil dan muestra de una alta intensidad. ${ }^{21}$ Sin embargo, ponerle un porcentaje es prácticamente imposible, aunque existe una fuerte contradicción, en todos los procesos electorales las denuncias son múltiples, pero en 2012 fue un factor punta de lanza para las impugnaciones que realizaron diversos partidos políticos.

La compra y coacción del voto es un fenómeno que está afectando severamente la competencia política. El fenómeno persiste porque existen las condiciones económicas del sujeto que intercambia su voto

${ }^{21}$ Un estudio que codificó de manera importante las conductas de compra y coacción del voto es: Estudio sobre las condiciones de la compra y coacción del voto, FLACSO, 2001, adicionalmente son relevantes los estudios de Alianza Cívica (www.alianzacivica.org.mx/ pparti.php). 
a cambio de dinero o un bien material, como también una carente cultura política en donde no se tiene conciencia que al vender su voto está cediendo su derecho inalienable para que otros decidan su apoyo político. Además el exceso de dinero en las campañas y lo cerrado de la competencia política hace que los actores en disputa recurran a la compra del voto como un insumo que les puede dar mayores posibilidades de obtener el triunfo electoral.

Por lo anterior, sólo es fundamental ratificar que la compra y coacción del voto es una realidad en México, y que esta conducta es la razón de ser de la justicia penal electoral, cuya obligación es inhibir esta clase de delitos y en su caso castigar su comisión. En razón de lo anterior, realizaremos una síntesis de las acciones de la FEPADE, institución que tiene el monopolio del ejercicio de la acción penal en México, esto es, recibe las denuncias, las procesa, en caso de existir los elementos constitutivos del delito, consigna y sigue el procedimiento hasta el final ante instancias judiciales.

\section{Los recursos humanos y financieros de la FEPADE}

En 2001 la FEPADE transforma su estructura interna aumentando su personal y sus áreas de operación. En aquella época en la FEPADE laboraban 300 servidores públicos, esta estructura se mantuvo hasta principios de 2007, en donde se redujo el personal un 30\%, ello derivado de una decisión de los órganos centrales de la Procuraduría General de la República justificada en que no era necesario ese personal en años que no hay elecciones. En 2012 el personal de la FEPADE es de 250 funcionarios.

Uno de los grandes problemas de la FEPADE es su falta de autonomía e independencia del Poder Ejecutivo. Los ejemplos al respecto son diversos, el presupuesto y el personal es asignado de manera discrecional por los responsables en turno de la Procuraduría General de la República, sin tomar en cuenta algunas veces las solicitudes apremiantes de la FEPADE. Mientras que la FEPADE tiene poco presupuesto, aproximadamente 110 millones de pesos por año, de esta cantidad el $92 \%$ es para pago de personal y el resto para investigar y prevenir el delito, el IFE y el TEPJF tienen recursos vastos, el del primero mencionado oscila entre cinco mil millones de pesos y el del segundo como 
dos mil millones de pesos. La FEPADE en comparación con el IFE recibe el $2.2 \%$ y con el TEPJF el 5.2\%. Un aspecto que es oportuno mencionar es que la FEPADE en algunas de sus funciones se auxilia por diversas áreas de la PGR, como es la policiaca, pericial y las delegaciones federales. Sin embargo, también lo es que para ellos la FEPADE no es prioridad, puesto que algunas veces es vista como una unidad administrativa externa. Además la ayuda es menor, por ejemplo, las delegaciones reciben la denuncia y en casos extremos realizan las primeras declaraciones, pero inmediatamente envían el expediente a la FEPADE. Lo mismo pasa en los tribunales federales, en donde los ministerios públicos federales son intermediarios en las notificaciones, puesto que todos los alegatos, recursos y formulación de pruebas son elaborados directamente por el personal de la FEPADE.

\section{Las averiguaciones previas que recibe la FEPADE}

El punto de partida del presente apartado es el año 2000, en esta época la FEPADE era una institución prácticamente desconocida, salvo los actores políticos, los ciudadanos no sabían de su existencia ni mucho menos conocían los delitos electorales. En aquel periodo la estructura de la FEPADE era menor, no contaba con recursos para hacer pública su función y no realizaba acciones de prevención del delito electoral. En consecuencia, era difícil que un ciudadano presentara una denuncia.

De enero de 2000 a julio de 2012, la FEPADE ha recibido 13426 denuncias por la posible comisión de delitos electorales. Como se aprecia en la gráfica 1, existen dos variables que se aprecian claramente, la primera que en año de elección federal las denuncias aumentan (2000, 2003, 2006, 2009 y 2012). La segunda es que aunque no existe año electoral las denuncias se siguen radicado, ello se debe principalmente a que los delitos electorales tienen una temporalidad permanente, en cualquier momento se pueden manifestar. Antes de proseguir, es necesario dejar claro que de las denuncias que se reciben en la FEPADE, entre un $85 \%$ y $90 \%$, dependiendo del año que se trate, están relacionadas con la alteración del padrón electoral, esto principalmente consiste en personas que obtuvieron su credencial de elector con datos falsos. Esto no debería constituir un delito electoral porque los que obtienen la credencial con datos falsos no lo hacen para fines 
electorales, sin embargo, de no estar tipificados, la FEPADE tendría un menor número de denuncias a las señaladas en periodo electoral y en los otros años, prácticamente ninguna. Por lo que la institución se quedaría trabajando sólo con las averiguaciones y procesos judiciales en marcha.

El motor que pone en marcha el proceso penal es la denuncia. En esta materia, el ciudadano que no está inmerso en los procesos electorales no tiene interés en denunciar, puesto que no percibe al delito electoral como un acto que genere un menoscabo a su integridad física o patrimonial. Además es evidente que en el país las instituciones procuradoras de justicia gozan de poca confianza derivado de su deficiente desempeño, razón por la cual no existe un incentivo por denunciar los delitos electorales. Es probable que el ciudadano piense que denunciar de poco va a servir, se pierde tiempo y puede ser que la persona que denuncia tome represalias en su contra. No es superficial afirmar que los delitos electorales casi no son denunciados por el ciudadano común, generalmente quien presenta las denuncias son funcionarios del IFE por alteración de padrón electoral, miembros de partidos políticos o representantes de candidatos.

Un aspecto que como primera impresión puede llamar la atención es el aumento de denuncias a la FEPADE a partir de 2007, ello oscila en un $50 \%$ en relación con otros años en los que no se celebraron elecciones. En principio se puede deducir porque es consecuencia de mayor posicionamiento público de la FEPADE o mayor responsabilidad ciudadana al presentar denuncias. Esto no es así, la razón porque aumentaron las denuncias es porque el IFE incorporó como mecanismo de verificación del padrón electoral un programa llamado "Detección de Registrados Duplicados AFIS" (Automated Fingerprint System 2006), el que aplicado reveló que 723 casos de personas que contaban con más de un registro con nombre distinto en el padrón electoral. Esta acción tuvo como resultado que el IFE presentara denuncias en la mayoría de los casos señalados. ${ }^{22}$ Por esta razón fue que también la FEPADE aumentó de manera exponencial el número de sentencias condenatorias, ya que de las denuncias presentadas la mayoría se acompañaban de pruebas irrefutables de la comisión del acto ilícito. Por ejemplo, una persona tenía dos credenciales con nombres diferentes, con fotografía y huella digital idéntica. Esta circunstancia

22 FEPADE, Informe Anual de actividades 2007, México, PGR, 2008, p. 20. 
se replicó en años subsecuentes, en 2008, 2010 y 2011, más del 93\% de las denuncias correspondían al ilícito anteriormente señalado. ${ }^{23}$

\section{Gráfica 1}

Averiguaciones previas iniciadas por año de enero de 2000 al 27 de julio de 2012

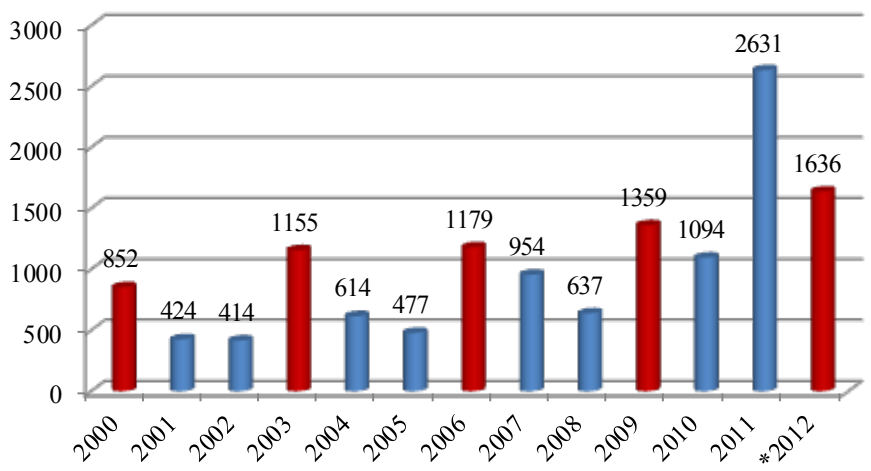

*Elaboración propia con datos de los informes mensuales que FEPADE entrega al IFE.

\section{Las determinaciones jurídicas de la FEPADE}

La FEPADE es sin duda una de las instituciones procuradoras de justicia que presenta mayores porcentajes de consignaciones en relación con el número de denuncias recibidas. Como lo indica el cuadro 1, las consignaciones año con año aumentan, en principio podría indicar que los delitos electorales crecen de manera permanente. Sin embargo, no es viable hacer un análisis lineal, como lo mencionamos la mayoría de consignaciones son producto de delitos relacionados con la alteración del padrón electoral, de personas que obtienen una credencial de elector con otra identidad y su incidencia en la denuncia depende de las consignaciones que realice el IFE cuando detecta duplicidades. ${ }^{24} \mathrm{Si}$ lee-

${ }^{23}$ Información obtenida de los informes mensuales que la FEPADE presenta ante el IFE.

${ }^{24}$ Para hacer un análisis del aumento de la incidencia delictiva por ilícitos que no 
mos la gráfica de manera literal se podría deducir que la FEPADE año con año aumenta su eficiencia, sin embargo no es así, el aumento del ejercicio de la acción penal obedece a las denuncias que presenta el IFE de alteración del padrón, que como hemos reiterado, la denuncia viene acompañada de pruebas contundentes que comprueban el ilícito. Es por ello que en 2011 cuando la FEPADE tuvo máximos históricos por consignación, el $97 \%$ fueron por el delito anteriormente referido (artículo 411 del CPF). ${ }^{25}$

En materia de incompetencia, a partir de 2007 se modificó la política de procuración de justicia en la materia y FEPADE empezó a conocer de otros ilícitos, que aunque no fueran estrictamente electorales se les daba curso. Por ejemplo, cuando se presentaba un fraude con una credencial de elector, con antelación a 2006, se conocía en la FEPADE, por lo que respecta a la falsificación de la credencial para votar y se mandaba al área correspondiente para que fuera consignado por fraude. Con la medida empleada a partir de 2007, se disminuyeron las incompetencias y al mismo tiempo se modificó el esquema de ser un órgano especializado en materia penal.

En lo que respecta a las reservas, en 2001 la Procuraduría General de la República emitió un criterio por el cual se trataba de dar celeridad a las averiguaciones previas, ello para evitar que existieran expedientes que duraran años en investigación. Para este fin consideró que el tiempo adecuado era de seis meses. Este criterio era flexible y si la indagatoria lo requería se podría ampliar, pero la mayoría de áreas se circunscribieron a ello. Si analizamos el cuadro 1, observamos que fueron cientos las averiguaciones previas que se mandaban a la reserva, ello fue consecuencia de que el Ministerio Público quería evitarse tener indicadores que no le favorecieran por tener una indagatoria que no podría resolver en menos de seis meses, lo que hacía era mandarla a la reserva. Este criterio se modificó a partir de 2007 es por ello que las reservas disminuyeron significativamente.

están relacionados con el padrón electoral es necesario contar con la información procesada por delito por año, datos que no fue posible obtener por no estar publicados.

25 Información obtenida de los informes mensuales que se presentan al IFE durante los meses enero a diciembre de 2011. 


\section{Cuadro 1}

Histórico de determinaciones de la FEPADE

\begin{tabular}{|r|c|c|c|c|c|r|}
\hline Año & Incompetencia & Acumuladas & Reservas & $\begin{array}{c}\text { No ejercicio } \\
\text { de la acción } \\
\text { penal }\end{array}$ & $\begin{array}{c}\text { Ejercico de la } \\
\text { acción penal }\end{array}$ & TOTAL \\
\hline $\mathbf{2 0 0 0}$ & 86 & 0 & 320 & 173 & 88 & 667 \\
\hline $\mathbf{2 0 0 1}$ & 125 & 0 & 323 & 362 & 52 & 862 \\
\hline $\mathbf{2 0 0 2}$ & 69 & 13 & 251 & 406 & 84 & 823 \\
\hline $\mathbf{2 0 0 3}$ & 200 & 60 & 246 & 511 & 100 & 1117 \\
\hline $\mathbf{2 0 0 4}$ & 173 & 35 & 261 & 471 & 82 & 1022 \\
\hline $\mathbf{2 0 0 5}$ & 152 & 15 & 176 & 402 & 106 & 851 \\
\hline $\mathbf{2 0 0 6}$ & 289 & 77 & 206 & 511 & 92 & 1175 \\
\hline $\mathbf{2 0 0 7}$ & 54 & 32 & 59 & 361 & 353 & 859 \\
\hline $\mathbf{2 0 0 8}$ & 74 & 30 & 50 & 248 & 716 & 1118 \\
\hline $\mathbf{2 0 0 9}$ & 99 & 64 & 111 & 284 & 688 & 1246 \\
\hline $\mathbf{2 0 1 0}$ & 125 & 35 & 90 & 309 & 861 & 1420 \\
\hline $\mathbf{2 0 1 1}$ & 90 & 26 & 43 & 502 & 1118 & 1779 \\
\hline $\mathbf{2 0 1 2}$ & 8 & 10 & 12 & 208 & 574 & 812 \\
\hline TOTALES & 1,544 & 397 & 2,148 & 4,748 & 4,914 & 13,751 \\
\hline
\end{tabular}

*Elaboración propia con datos hasta el 30 de junio de 2012, obtenidos de los informes mensuales que la FEPADE presenta al IFE.

Un dato que puede ser sorprendente de la FEPADE es un aumento constante en los ejercicios de la acción penal. Como lo indica la gráfica 2, a partir de 2007 el cambio fue radical. Es probable que en México no exista una sola institución procuradora de justicia que presente esos resultados, por ejemplo en lo que va de 2012 , el $70.7 \%$ de las averiguaciones previas procesadas se consignaron. Sin embargo esos porcentajes requieren procesarlos en su real dimensión. Para saber con certeza la efectividad de la FEPADE, se requiere eliminar de sus estadísticas los delitos comprendidos por alteración del padrón electoral. En 2011 de 1118 consignaciones hechas por la FEPADE, 1082 fueron por artículo 411 del CPF, el resto, 36, fueron por otros delitos electorales. Hasta el 30 de mayo de 2012, de 574 consignaciones, 566 fueron por artículo 411 del CPF, 7 por artículo 403 del CPF y la restante que es una, por artículo 211 del CPF, que dicho sea de paso no debería ser delito electoral. 


\section{Gráfica 2}

Histórico de determinaciones de 2000 al 30 de mayo de 2012

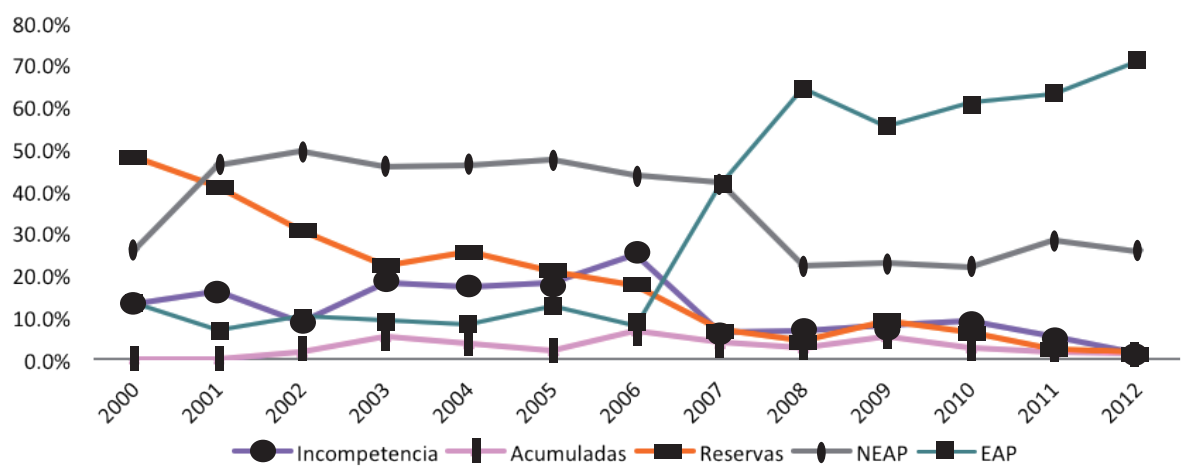

*Elaboración propia con datos hasta el 30 de mayo de 2012, con datos obtenidos de los informes mensuales que FEPADE presenta al IFE.

\section{Los procesos penales electorales}

Al igual que el porcentaje de efectividad en las consignaciones, la FEPADE, como lo indica el cuadro 2, tiene una alta efectividad. Ello obedece a dos motivos, uno anteriormente señalado como es el relacionado a las consignaciones por artículo 411 del CPF, que prácticamente en la denuncia viene acompañada de las pruebas plenas de culpabilidad emitidas por el IFE, y por el otro sentido, el cuidado extremo que se tiene en la FEPADE por los procedimientos judiciales. El marco institucional que creó a la FEPADE es muy claro al delimitar que tiene el carácter de fiscalía especializada, es decir, al ser una instancia que únicamente está creada para la materia penal electoral, busca que con la experiencia acumulada domine completamente la materia. La FEPADE no es igual que otras dependencias de la PGR, y lo que es más, es bastante diferente por muchos motivos. Los delincuentes electorales obedecen a otra lógica de la delincuencia tradicional. Además en una delegación federal de la PGR, se reciben denuncias por innumerables delitos, lo que no permite que los ministerios públicos conozcan a plenitud todas las áreas del derecho penal federal.

Es oportuno reconocer que se requiere cuidado extremo para tener un $100 \%$ de sentencias condenatorias como sucedió en 2001, 2003 y 2006. También tener más del $90 \%$ de eficacia de 2007 a 2012 conside- 
rando los cientos de los procedimientos. Aunque casi su totalidad fueron por el artículo 411 del CPF, de cualquier forma para obtener ese resultado se tuvo que cuidar al máximo los procedimientos de principio a fin. El $95.6 \%$ que se tiene acumulado de 2000 a mayo de 2012 de sentencias condenatorias, no tiene precedente en México en otras instituciones procuradoras de justicia. Con estos datos se confirma que la FEPADE al menos ha cumplido en el cuidado extremo que tiene en sus procedimientos judiciales, no obstante que el personal que se tiene en relación con la carga de trabajo es restringido.

\section{Cuadro 2}

Procesos judiciales de 2000 al 30 de mayo de 2012

\begin{tabular}{|r|r|r|r|r|r|r|r|}
\hline & $\begin{array}{c}\text { AP } \\
\text { iniciada } \\
\text { s }\end{array}$ & EAP & $\begin{array}{c}\text { \% de } \\
\text { consign } \\
\text { a-ciones }\end{array}$ & $\begin{array}{c}\text { Condena } \\
\text { torias }\end{array}$ & $\begin{array}{c}\text { Absoluto } \\
\text { rias }\end{array}$ & Total & Eficacia \\
\hline 2000 & 852 & 88 & 10.3 & 31 & 3 & 34 & $91.2 \%$ \\
\hline 2001 & 424 & 52 & 12.3 & 46 & 0 & 46 & $100.0 \%$ \\
\hline 2002 & 414 & 84 & 20.3 & 40 & 3 & 43 & $93.0 \%$ \\
\hline 2003 & 1155 & 100 & 8.7 & 57 & 0 & 57 & $100.0 \%$ \\
\hline 2004 & 614 & 82 & 13.4 & 59 & 1 & 60 & $98.3 \%$ \\
\hline 2005 & 477 & 106 & 22.2 & 61 & 3 & 64 & $95.3 \%$ \\
\hline 2006 & 1179 & 92 & 7.8 & 65 & 0 & 65 & $100.0 \%$ \\
\hline 2007 & 954 & 353 & 37.0 & 59 & 2 & 61 & $96.7 \%$ \\
\hline 2008 & 637 & 716 & 112.4 & 140 & 11 & 151 & $92.7 \%$ \\
\hline 2009 & 1359 & 688 & 50.6 & 187 & 15 & 202 & $92.6 \%$ \\
\hline 2010 & 1094 & 861 & 78.7 & 199 & 13 & 212 & $93.9 \%$ \\
\hline 2011 & 2631 & 1118 & 42.5 & 349 & 13 & 362 & $96.4 \%$ \\
\hline $2012 *$ & 1636 & 574 & 35.1 & 97 & 7 & 104 & $93.3 \%$ \\
\hline Total & 13426 & 4914 & 36.6 & 1390 & 71 & 1461 & $95.6 \%$ \\
\hline
\end{tabular}

* Elaboración propia con datos hasta el 30 de mayo de 2012, obtenidos de los informes mensuales que FEPADE presenta al IFE. En 2008, se señala un $112.4 \%$ de consignaciones, ello se debe a que de los datos referidos, algunas denuncias se presentaron e integraron durante 2007 y se consignaron en 2008. 


\section{$X$. Los delitos electorales en su relación con los derechos difusos y colectivos}

La verdadera particularidad de los delitos electorales no ha permeado en el imaginario colectivo. García Ramírez establece que no hay democracia sin derechos humanos, y es por eso que el derecho penal electoral busca tutelar un bien jurídico inalienable al ciudadano como es elegir gobernantes y su forma de gobierno. Por lo que toda conducta que violente ese acto constituye una ofensa inferida a la sociedad. ${ }^{26}$ Sin profundizar en los valores de la democracia representativa, es natural deducir que el derecho penal electoral tiene una faceta de múltiples factores. "Su importancia, como un instrumento de derecho público, tiene como objeto legitimar la representación política; garantizar la estabilidad social para la suma de voluntades en la definición de los asuntos públicos; la pertenencia nacional para la razón de estado representado por el ejercicio de un poder individual y en el marco de la ley fundamental". ${ }^{27}$ Cuando se afecta este bien genera un grave perjuicio a la sociedad en su conjunto.

El derecho penal electoral está íntimamente relacionado con el entorno de la competencia político-electoral, sin embargo, algunas veces no se aprecia su total magnitud. Los delitos electorales se crearon para evitar que se dañe el voto libre y secreto. Lo que es un hecho, es que sectores amplios de la población no están valorando la importancia de lo que implica el acto de votar. Por una parte están los integrantes de partidos políticos que durante los procesos electorales compran y coaccionan el voto, por el otro, los sujetos que se dejan intimidar, comprar o que intercambian su voto por un bien material. Lo lamentable es que en estos actos no se perciba la magnitud del daño en la sociedad, en el sistema de gobierno y a los principios básicos del derecho público, que regula la convivencia humana.

Los delitos electorales tutelan los valores constitucionales del sufragio, el desempeño adecuado del proceso electoral y la certeza del resultado de las elecciones. El bien jurídico que tutelan se establece en el entorno de los derechos políticos y sociales del ciudadano. Si

26 García Ramírez, Sergio, "Delitos en materia electoral”, p. 17, en www.biblio. juridi cas.unam.mx/libros/2/756/24.pdf.

27 Díaz Santana, Héctor, "La importancia de los delitos electorales en el sistema mexicano", cit., p. 81 . 
estos se afectan, causan un perjuicio grave a la sociedad que en primera instancia es invisible. Es por ello, que se pueden considerar en el entorno de los derechos difusos y colectivos. Fix-Zamudio los define como los "derechos subjetivos e intereses legítimos que corresponden a personas indeterminadas, pertenecientes a diversos grupos sociales, que se encuentran distribuidos en amplios sectores, de manera que no resulta fácil el establecimiento de los instrumentos adecuados para la tutela de los propios intereses". ${ }^{28}$ Por su parte Cabrera Acevedo considera que los derechos difusos y colectivos pertenecen a "una comunidad de personas indeterminadas e indeterminables", por eso los remite para su ejemplificación al medio ambiente sano y al desarrollo sustentable. ${ }^{29}$

Es fundamental que el desarrollo a futuro de los delitos electorales se conciba bajo esta figura jurídica. Si hacemos una analogía con los delitos ecológicos, podemos encontrar sentido en el ejemplo de una conducta reiterada como es tirar la basura en un río, con el paso del tiempo se contaminará y la sociedad que se provee de esa agua se enfermará. En este sentido, si en México se sigue comprando y coaccionando el voto como un mecanismo propio de los procesos electorales, nuestra democracia en poco tiempo se verá desbastada. Al respecto existe doctrina en México, el Cuarto Tribunal Colegiado en Materia Civil del Primer Circuito, establece que los intereses colectivos o difusos pertenecen a todos los miembros de la sociedad y no existe posibilidad de fraccionarse para cada uno, ya que tutelan una amplia gama de derechos, que de no respetarse pueden perjudicar "los intereses de todos los ciudadanos en general", 30 por ello es fundamental "preservar los valores protegidos y alcanzar los fines perseguidos, hacia una sociedad más justa". ${ }^{31}$ Los intereses difusos y colectivos tienen como objeto preservar los valores protegidos, para construir sociedades más justas y velar por los intereses de los ciudadanos. Esta acción constituye una de las responsabilidades del derecho penal electoral.

28 Fix-Zamudio, Héctor, Simposio, los abogados mexicanos y el ombudsman (memoria), México, Comisión Nacional de Derechos Humanos, 1992.

29 Cabrera Acevedo, Lucio, El Amparo colectivo protector del derecho al ambiente y de otros derechos humanos, México, Porrúa, 2000.

30 Tesis I.4o. C.137.C, Tesis Aislada, Seminario Judicial de la Federación y su Gaceta, Novena Época, t. XXVII, abril de 2008, p. 2381,

${ }_{31}$ Idem; Tesis I.4o. C.136.C, Tesis Aislada. 


\section{Conclusiones}

El poder sintetizar doce años de justicia penal electoral federal es una labor compleja y en algún momento hasta subjetiva. Los resultados alcanzados a la fecha están lejanos de cumplir de manera integral su responsabilidad institucional. Los delitos electorales y la FEPADE se crearon para inhibir o castigar las conductas que violenten el voto libre y secreto y a la fecha no existen evidencias que la labor se cumpla de manera plena. En todos los procesos electorales federales se denuncian acciones de compra y coacción del voto. De ello no está ajeno ningún partido político. En todos los procesos electorales se han denunciado por la comisión de delitos electorales y de estos prácticamente las sanciones son mínimas en relación con la magnitud del fenómeno. En 2012, la compra del voto masiva fue parte de la impugnación electoral.

Los problemas derivados por las irregularidades de los procesos electorales en el país no han disminuido y es más, en algunos lugares están aumentando su incidencia. El derecho penal electoral poco ha contribuido a combatir este fenómeno que está desdibujando la esencia básica de la democracia representativa del país.

En los últimos doce años la justicia penal electoral prácticamente está desapareciendo. En este periodo no se han realizado cambios a las normas electorales y a la FEPADE se le disminuye periódicamente el presupuesto y el personal. Prueba de lo anterior, es que las plazas en 2012 no aumentaron, no obstante la demanda en materia de procuración y prevención y lo que es más grave, las plazas que se desocupan se congelan. La FEPADE al ser una institución dependiente del Poder Ejecutivo, depende para su ejercicio de la decisión que este tenga o que el procurador general de la República en turno considere adecuado otorgar. La experiencia demuestra que en los últimos seis años fueron pocos los apoyos recibidos, ello obedece a una falta de sensibilidad o conocimiento de la responsabilidad institucional de la FEPADE. No obstante que la labor de esta institución puede ir de la mano de la garantía de la paz social derivado de la estabilidad en las elecciones.

Un problema adicional es la falta de temor en los delitos electorales, por tal motivo, no existen condiciones que inhiban su comisión. Tanto los actores políticos como los ciudadanos saben que difícilmente van a ser sancionados si comenten delitos electorales. Una investigación 
realizada por la FEPADE en 2006 con el apoyo de profesores de la UNAM, determinó que la ciudadanía no le teme a los delitos electorales, "por delitos electorales nadie se va a la cárcel (grupo de enfoque realizado en Ixmiquilpan, Hidalgo)". ${ }^{32}$ Por lo anterior se requiere de una instancia mucho más efectiva en lo que respecta a la sanción de los delitos electorales.

El dilema para los próximos años es cómo modificar el marco normativo de los delitos electorales. Es decir, si aumentan los tipos penales y las sanciones será suficiente para hacer una justicia penal electoral más efectiva. De ser así y en consecuencia la situación que prevalece es la misma, quiere decir que no fue la solución. Para evitar la comisión de delitos electorales se requiere modificar el esquema global en la forma como se realizan los procesos electorales actualmente.

El derecho penal electoral encuentra a su enemigo en la llamada estricta aplicación de la ley. Actualmente son innumerables los hechos que oscilan entre la comisión de delitos electorales y las formas irregulares del desarrollo de las campañas políticas en México. Otorgar una despensa a cambio de un voto es un delito; regalar una despensa como una acción de proselitismo político no constituye ni siquiera una falta electoral. Como se aprecia la línea es sutil y el hecho y el efecto puede ser el mismo.

En el contexto ideal el mejor escenario sería que no existiera la FEPADE, en el objetivo es necesaria. Si las elecciones se desarrollaran cumpliendo las reglas positivas y las reglas subjetivas del respeto a los valores de la democracia representativa, la FEPADE no tendría razón de ser. Por el contrario, si se fragmenta la equidad y la sana competencia, se requiere una institución que vele por los intereses ciudadanos y del derecho público.

Una pregunta que es necesario hacer es por qué los actores políticos no han modificado los delitos electorales desde hace 16 años, será porque las reglas actuales les funcionan con comodidad y les permiten un margen amplio de discrecionalidad en la comisión de irregularidades sin ser sancionados. Lo que poco se reflexiona, es que esas reglas formales e informales de la competencia política, están permitiendo un juego sucio donde hasta ahora salen golpeados con pocas conse-

32 FEPADE-PNUD, Análisis de los delitos electorales de México en el marco de la compra y coacción del voto, México, 2006. 
cuencias. Sin embargo, de seguir así propiciarán que en algún proceso electoral las consecuencias sean graves y de difícil solución.

En materia penal, en los últimos doce años los esfuerzos por modernizar a la justicia se han reflejado en la construcción de nuevas instituciones, el camino planeado está previamente definido y los avances son limitados. Los juicios orales que son el cambio estructural de mayor visibilidad tienen claras dilaciones de operación, no obstante ello, el esfuerzo existe y al menos se está realizando por mejorar las instituciones procuradoras e impartidoras de justicia penal. En lo que respecta a la justicia penal electoral, el descuido en la materia se debe corregir. El IFE y el TEPJF están activos y constantemente modernizan sus instituciones y procesos. La FEPADE es una institución que sobrevive, pero que requiere transformarse, las reformas que se podrían hacer son innumerables, desde mayor fortaleza y responsabilidad en la designación del titular por un periodo fijo e inamovible, garantía de autonomía funcional, aumento en su personal y presupuesto, reforma estructural en el marco normativo y la integración de nuevos esquemas funcionales para la prevención del delito electoral.

\section{Bibliografía}

Barreiro Pereda, Francisco, "Los delitos electorales en la legislación penal mexicana”, Justicia Electoral, vol. II, núm. 3, 1993.

CABrera Acevedo, Lucio, El amparo colectivo protector del derecho al ambiente $y$ de otros derechos humanos, México, Porrúa, 2000.

Díaz-Santana, Héctor, "El ejercicio de las instituciones electorales en la manipulación del voto en México", Perfiles Latinoamericanos, núm. 20, junio de 2002.

- - - "LA importancia de los delitos electorales en el sistema electoral de México", en Estrada Camargo, Manuel y Sáenz López, Karla (coords.), Elecciones, gobierno y gobernabilidad, México, Instituto Federal Electoral-Universidad Autónoma de Nuevo León, 2010.

Esparza, Bernardino, Constitucionalización de los delitos electorales en la legislación mexicana, 1812-2009, México, Instituto Nacional de Ciencias Penales, 2009. 
FEPADE, Informes Anuales de actividades, 2002, 2006, 2007, 2008, 2009, PGR, México.

Fix-ZAmudio, Héctor, Simposio, los abogados mexicanos y el ombudsman (memoria), México, Comisión Nacional de Derechos Humanos, 1992.

Fromow, María de los Ángeles, "Los delitos electorales en México", Revista Mexicana de Justicia, Sexta Época, núm. 3, 2002.

García Ramírez, Sergio, "Delitos en materia electoral", en www.biblio.juridicas.unam. $m x /$ libros/2/756/24.pdf.

González de la Vega, René, Derecho penal electoral, 3a. ed., México, Porrúa, 1994.

López Pintor, Rafael, El fraude electoral en las democracias emergentes: conceptos básicos para una evaluación, Washington DC, IFES, 2010.

Marquez Piñero, Rafael, "Delitos de peligro abstracto”, en García Ramírez, Sergio e Islas de González Mariscal, Olga (coord.), Análisis del nuevo Código Penal para el Distrito Federal, México, UNAM, Instituto de Investigaciones Jurídicas, 2003.

Montoro Ballesteros, Alberto, "En torno a la idea de delito político (Notas para una ontología de los actos contrarios a Derecho)", Anales de Derecho, Universidad de Murcia, núm. 18, 2000.

Orozco Henriquez, Jesús J. y Silva Adaya, Juan Carlos, "El régimen represivo electoral (con especial referencia a las sanciones administrativas), Revista Mexicana de Justicia, Sexta Época, núm. 3, 2002.

Pérez Fernández del Castillo, Germán et al. (comps.), Memoria histórica de la transición democrática en México (1977-2007). Documentos básicos para entender el cambio político, México, Porrúa, 2009.

Reyes Tayabas, Jorge, Análisis de los delitos electorales y criterios aplicativos, México, PGR, 1994.

Silguero Estargan, Joaquín, La tutela jurisdiccional de los intereses colectivos a través de la legitimación de grupos, Madrid, Dykinson, 1995.

Toqueville, Alexis de, La democracia en América, México, Fondo de Cultura Económica, 1994.

Zaffaroni, Eugenio Raúl, Manual de derecho penal, México, Cárdenas Editor y Distribuidor, 1991.

Zamora Jiménez, Arturo, Delitos electorales, México, Ángel editores, 2003. 